\author{
Igor K. Liseev \\ Institute of Philosophy, RAS
}

\title{
NATURE IN THE MODERN PHILOSOPHICAL DISCOURSE
}

Philosophy of nature is the part of philosophy which investigates mainly the foundations of nature and the limits of its existence. The philosophy of nature, emerged in ancient times, was the first form of philosophy, and it passed through the whole history of philosophy. It had periods of coming to life, getting into blossom, decline and the actual disappearing from the philosophical scope. Despite the differences in the comprehension of the philosophy of nature in various periods of its evolution, and despite the variety of its forms and doctrines, it had a common basis: it dedicated its efforts to comprehending nature as the whole entity, and to comprehend various levels of nature by means of deductive constructions. Many ideas put forward in the philosophy of nature promoted the development of many branches of science. For example, the notion of primordial elements in the early Greek philosophy was considered as one of the stable principles making foundations of various forms of nature. A new line in the ancient philosophy of nature was initiated by Anaxagoras and Pythagoreans who had attempted to present nature as the fruits of some ideal primordial principles revealing the foundations of the structure of nature. Aristotle essentially contributed to the philosophy of nature by proposing the model of nature as something created and governed by the internal aim.

Hereby, nature acts as some autotelic, self-proposed, self-generating living entity, and self-producing its own various forms. The driving force of this generative ability is entelechy, inherent in the entity itself. The Renaissance philosophers of nature multilaterally criticized the medieval theological views; they grasped the philosophy of nature as aimed at the real studies of nature which comprehended its reasons and principles of the world given us through our senses. In the philosophy of nature in the modern times the leading and initial image was the nature in the quality of sophisticated mechanical structure, as the body, aggregated of prime material elements. Such an approach gave possibility to consider the object of research in its autonomous independent existence, to examine and present its elements and correlations between them. Many important ideas were introduced by Goethe in his Naturphilosophie: the scientific routine is enriched by Goethe's considerations of the symbol, joining natural and spiritual principles, the theory of type in morphology, resolving the problem of the general as a sample for singular.

Schelling's Naturphilosophie enormously influenced natural sciences by introducing new stimulating ideas. The thinker put forward a new understanding of nature as a grade precedent to spirit. The transition from the nature to the spirit, according to Shelling, constitutes the ascending from unconscious spirituality of nature to the well known human spirit. This transition aims at the full comprehension of nature, nature returning to its own essence. Consequently, the nature is revealed as being identical with something that we comprehend inside us as reasonable and conscious. Schelling presents the Naturphilosophie as a doctrine of the grades of the unfolding spirituality in nature. The Naturphilosophie reached its summit in the principles formulated by Hegel. As trail-blazer in many aspects, Hegel demonstrated that in philosophy of nature objective is correlated with subjective. 
Every hypothetical relation has to reveal, according to Hegel, some specific form of practical relation and, hereby, to reveal proper aspects of subjectivity, forming the basis of objective mental structures. In other words, Hegel proved that the philosophy of nature does not only reveal the universal in the world, but describes objects existing in the nature from the point of view of their relations to the man's sensuality.

Nevertheless, despite all its achievements, Naturphilosophie of the XIX century gradually disappeared from the philosophic scope as an independent matter. This vanishing was explained by the fact that in its various conceptions, as a rule, the substitution of regulatory principles for constitutive ones took place. In the Naturphilosophie the unjustifiable transferring of concrete historical principles and of the methods of scientific cognition, which are effective in the concrete cognitive and cultural situation of real social environment, was put in practice on nature itself. The main presumption of Naturphilosophie was supposition of the absolute observer, staying beyond the history and beyond the nature, who wanted to comprehend the nature as it is in itself. Those pretensions of Naturphilosophie, as the time went by, when main philosophic settings and directions being changed, were taken as inconsistent, and, as a result, were thrown away by intellectual community. Nevertheless, the new philosophy taken over the place could not fill the vacuum formed when Naturphilosophie disappeared. It can be explained by the fact that the philosophy of natural sciences was, first of all, the philosophical analysis of the natural sciences, focused on their methodology and logic. Those researches rejected the ontological explanatory schemes and models, the axiological aspects, the aspects of the interaction of human being and nature as the subjects to be valued. It abstracted sciences from the directions of activity, praxiological, civilization orientations.

The absence of all these fundamental factors in the philosophy of the twentieth century, of all settings of life's reasons and meanings, gave rise to an increasing profound civilization crisis. Because of this, in the second half of the twentieth century, the necessity of formation of a new philosophy, having broader aims and the domain, increased. From some world-schematic system existing out of man and independently of man, the today philosophy of nature is changing into philosophical reflections and meditations of man who exists in nature, and who gets involved in the certain net of relations with nature. Philosophy of nature is becoming philosophical reflections on ontological prerequisites, cognitive, epistemological principles and views, values and activity appreciations of man in his new relationship with nature. These reflections determine a new view of nature and new principles of interaction with it on the basis of the new prerequisites.

Recently the necessity of creation of a new philosophy of nature is evident, in as much as the twentieth century natural science deals with various patterns of nature and ontological schemes and models, which frequently oppose one to another and are not connected. Nevertheless, in the scientific community the process of revealing the necessity of a new philosophy of nature occurs very slow. But the emerging and application of new essential scientific theories in the twentieth century serve as a conviction that such branch of philosophy is extremely important.

My vision of the significance of contemporary philosophy of nature is presented in the book "The Philosophy of Nature: Co-evolutionary Strategy", Moscow 1995, written by R.S. Karpinskaia, A.P. Ogurtsov and I.K. Liseev. The authors noted that the depth of philosophical knowledge is different in every country, being dependent on the number of social and cultural peculiarities of education. Marxist philosophy, being educated in USSR as 
compulsory, did not contribute at all to the evolution of the philosophy of nature. Marxism severely criticized the Naturphilosophie of the XIX century, first of all, the Hegelian Naturphilosophie. It rejected a possibility and actuality of the philosophy of nature at all. The 'antinaturphilosophical' charge of Marxism, preconditioned by its sociologism, and its anxiety to explain everything by social particularities of certain social and economic formation gave rise to restricting philosophy of science to methodology and logic. One of the important consequences of this restriction was the negation of clarification and analysis of ontological schemes and models which are universally (in time) effective for natural sciences.

The knowledge of the philosophy of nature is necessary for a deeper comprehension of the structure of philosophical knowledge. In the past as well as in the recent times no one philosophical system was able to work without applying general principles of nature, that is, without a specific philosophy of nature. The knowledge taken from philosophy of nature is important and indispensable for the comprehension and interpretation of scientific results, since philosophy of nature sets the points of orientation for building up the whole pattern of nature. We need knowledge offered by philosophy of nature to grasp the logic of evolution of natural sciences theories. We have to confess that natural sciences depend to a great extent on the world pattern which is elaborated mainly by philosophy. The idea of evolution, firmly established in biology of the nineteenth century, recently has become a paradigm of the whole natural science. From the fundamental idea of biology it has been converted into a general mode of thinking which influences more and more cosmology, literary studies, linguistics, or crystallography.

Evolutionary biologists, beginning from Darwin, talked about evolution strategy, keeping in mind the great correspondence of animals with their environments; this correspondence being produced as a result of the natural selection of adaptive indexes expressed itself more vividly in mimicry. In the seventies and eighties of the twentieth century biologists began to speak about stable evolution strategies in the behavior of members of the eco-system, that is, about strategies which cannot be improved by means of some alternative strategy, given that a sufficient number of members of eco-system accepted it.

Achievements of evolutionary biology of the twentieth century, to mention firstly ecology, ethology and genetics of eco-systems, demonstrated the importance of coevolution in the formation of communicative systems where the joint evolution is needed for transmitting and receiving systems, in explanation of different forms of communicative collective behavior of social animals etc. The idea of co-evolution emerged to explain the symbiotic interactions. Yesterday it was a marginal one, but now it is being realized in all its philosophical profundity and is becoming the central idea for evolutionary mode of thinking. In various parts of biology the topic of gene-cultural co-evolution, joint evolution of human psyche and social and cultural evolution, co-evolution of the nature and the man is being extensively elaborated. Nowadays the idea of co-evolution is coming into the program of the number of natural scientific disciplines. It requests to change thoroughly our scientific settings. If we do not change our mentality, if we do not convert the idea of co-evolution into the strategy of the natural scientific method and philosophical considerations of the nature, we will have a little hope to move forward in our attempts to elucidate the interconnections between the nature and the man, between evolution of psychology and behavior of animals, on the one hand, and man, on the other, between biological and socially-cultural evolution. 
The idea of co-evolution, dealt as a program for natural science at the enc of the twentieth century is set as a basis of the elaborated and accepted understanding of the philosophy of nature. We were eager not only to emphasize the significance of the idea of co-evolution for modern viewing of nature, but, moreover, we are fully conscious of the most important characteristics of co-evolution in the natural scientific and philosophical comprehension of the nature.

The co-evolutionary strategy enables scientists to interpret the results of sientific research within the limits of competence of every scientific discipline, to treat results of observations, measurements, experimental investigations, taking into account a lecisive vector inside natural eco-systems and biocenosis.

The co-evolutionary strategy enables us to be aware of scientific facts obtainzd from research works concerning nature, to explain these facts and processes by the assumption of their relation to anthropogenic influence on natural landscapes and ecological systens. The co-evolutionary strategy also enables the mankind to foresee negative consequences of human activity for nature, and to recommend how to evade these negative consequences or to minimize them.

The co-evolutionary strategy enables scientists to overcome the gap between the evolutionary approach to nature and the evolutionary principles concerning the man. It enables science to synthesize evolutionism in biology with evolutionism in social and cultural sciences. Hereby, it offers possibility to overcome limits of sociologism and historicism which negate the importance of bio-anthropologic factors in social and cultural evolution. As the evidence of the sociologism limitations it is possible to quote wel known Marx's words, that nature, as it is, does not exist, or words of J. Ortega y Gasset tiat man does not have nature, for him there is only history.

The co-evolutionary strategy proposes new perspectives of linking natural anl social sciences, pointing out how to seek new units and new ways of comprehending connections of various ethnic, national, social and cultural communities with natural and gecgraphic conditions. There is a new tool for joining and combining the evolution of nature and the man, of biosphere and noosphere, civilization and culture. Among new notions there are the notion "place-development", used in geographic investigations by "euroasianists" and then by P.N. Milukov in the analysis of history of Russian culture, the notion "chronotop" put into practice by A. Oukhtomskij and vastly used by M.M. Bakhtin in the philosophy of culture, the notion of "challenge" from the part of environment, and "response" fom the part of civilization, proposed by English historian A. Toynbee and used by L.N. Gunilov in his doctrine of ethnogenesis.

The co-evolutionary strategy forms and approves new landmarks of human actve life, sets new ecological regulations of the nature management, as well as of the mantfacture (transfer from monocultures to polycultures and adaptive strategy in agriculture, development of the biologic means of protection, non-wasted technology etc.), iets the norms of ecologic equilibrium and dynamic equilibrium of man and nature. This new strategy elaborates law regulations concerning the intrusion of the man into natural ecosystems, indicating values of biospherical ecological ethics, destined to sustain, protect and expand the life and to increase its diversity. Hereby, the deep sources of the ecological crisis are evident, and the ways out of it are indicated, as the human productive activity could serve for the biosphere condition improving, that is, get a sophisticated corelation between the order of biosphere and of noosphere. 
The co-evolutionary strategy contributes to the development of a critical vision and independent mentality, indispensable for mastering all intricate ways of contemporary human existence.

The co-evolutionary strategy is one of the strategies essential in modern natural science, the most prospective and powerful one of all now existing. It should be emphasized that in the modern natural science with the program and strategies appeared in the nineteenth century and in beginning of the twentieth century the new program is formed and thoroughly different strategy is being created, namely a co-evolutionary one.

One of the significant tendency in the twentieth century philosophy was the rejection of the Naturphilosophie. This tendency was embodied, firstly, into the orientation of philosophy toward epistemology (empiriocriticism, phenomenology, pragmatism), or toward methodology and logic of science (neokantianism of Baden and Marburg school, operationalism, neo-positivism, critical rationalism). Nevertheless, within the logical and methodological analyses of science a new assemble of problems cropped up which are related to the philosophy of nature. Those problems come out of the narrow frame limiting the whole philosophy to epistemological and logic-methodological investigations. That assemble of problems is connected with ontological models present in every scientific discipline. These ontological models are different in their contents, as well as in their versatility. They range from ideal objects, formed by theory and correlated with an empiric reality, to the image of reality and its levels characteristic of every scientific discipline (levels of physics reality in the system of physical sciences, levels of biological reality in the system of biological knowledge etc.). The notion of model can be extended to the scientific world-pattern, created by the whole system of natural sciences. Different ontological models existing in one and the same scientific discipline sometimes oppose each other, difficult to be joined. The specific work of logicians, methodologists and philosophers is needed to think over models' essence, their correlations with each other, to rationalize and to put them in order. Revealing ontological models, making foundations of the number of scientific disciplines constituted the main target of Nicolai Hartman's philosophy of nature and some other adepts of critical realism. The objects of that revealing were ideas of levels of reality in the philosophy of emergent evolution (S. Alexander, A.O. Lovejoy and others).

As the result of the negation of philosophy of nature in the twentieth century, the ontology, being developed in various philosophical sub-fields, was occupied mainly by the existentialistic selfhood entity and history. Philosophy was limited mainly by the analysis of true, authentic existence of the individual which is revealed at the structures of troubles, fear, transitory character of man's life. This reducing of ontology to man's existence gave rise to the fact that K. Jaspers' and J.P. Sartre's existentialism, the fundamental ontology of M. Heidegger, came forward with the criticism of technical instrumental relation of man to nature, hidden in natural science and in its forms of rationality. The gap between naturalscientific and humanitarian cultures reveals itself in the rejection of the philosophy of nature, in the disappearing of the philosophical exploration of nature from the more substantial philosophic doctrines of the twentieth century, in the absence of ontological constructions based on natural sciences.

The cultural and historical school of philosophy represented at the beginning of the twentieth century by W. Dilthey in Germany, A.N. Whitehead and R.D. Collingwood in England, put in the foreground the comprehension of the idea of nature, revealing historic mutations which occurred in nature. That approach could be realized either in the course of 
becoming aware of the shift in historic understanding of nature, happened in the twentieth century philosophy, or in the course of building of a new philosophy of nature, starting from the social and cultural determination of the comprehension of nature, from the relation of man to nature. The first way was taken by Whitehead. He supposed that a new image of nature in the $20^{\text {th }}$ century intended its comprehension as a complex of events and processes. The starting point for Whitehead's "cosmic philosophy" was the notion of organismic processes, being expanded on the whole Universe. The second way was taken not only by philosophers-Marxists (A. Gramsci, G. Lukács), but also by philosophers who saw in nature a way for the representation of theoretic and practical relations of the man to the world (S. Moskovici). Certainly, that way was normal for historians of philosophy which paid attention to the comprehension of its own kind of nature at the various periods of human history ( $R$. Lenoble, B. Token and others). The most interesting fact is that outstanding natural scientists of the twentieth century, physicists (K.F. von Weizsäcker, D. Bohm, W. Heisenberg) and biologists (K. Lorenz), acknowledged the historical character of comprehension of the nature and began to underline the possibility, and even necessity, of the reconstruction of the philosophy of nature on the social, cultural and historical bases. In an unambiguous way they described Naturphilosophie as the degeneration of the philosophy of nature, and connected it with the position, when investigator got distanced from the object to be investigated. The presumption of Naturphilosophie consists in taking the position of some absolute observer, staying out of history and above of science, but being able to comprehend the whole nature. No doubt, pretensions of Naturphilosophie, understood in such a way, to the objectively and integral comprehending of nature, are inconsistent and non-veridical. The rejection of Naturphilosophie, common in philosophy as well as in sciences, is compensated now by the search for others social and cultural bases for the comprehension of nature. For example, W. Heisenberg, famous physicist of the twentieth century, begins his article "Das Naturbild der heutigen Physics" with the rejection of significance of the Naturphilosophie for physics: "As distinct from past times, the recent relation to nature unlikely founds its expression in unfolded Naturphilosophie; now it is determined by science and engineering"'.

Really, the image of nature at the twentieth century became more complicated. It is not only differentiated, it crumbled. Semantic connections between ontological models of the various sciences, and also inside of the one and the same science, are hardly seen and sometimes not compatible with each other. The discussion between representatives of various theories and branches is preconditioned by the defending of alternative ontological models and of different scientific interpretations of reality. For example, two theories of light exist in physics: the corpuscular theory and the wave one, which were developed as a result of electrodynamics doctrine, according to which the light differences from radio waves and X-rays only by length of the wave. The ontological models used in these theories are thoroughly different. One more example: the discussion between A. Einstein and $\mathrm{N}$. Bohr concerned not only the fullness of the quantum mechanical description, but also the difference between their ontological models. Einstein insisted on fundamental significance of the field as ontological model of physics, claiming the idea of the world as existing objectively in space and time, the world being an object of observation from exterior. $\mathrm{N}$. Bohr insisted to another understanding of ontological models: the objective description is

\footnotetext{
${ }^{1}$ W. Heisenberg, Das Naturbild der heutigen Physik, Hamburg 1955, p. 7.
} 
impossible, the aim of quantum mechanics is not to about atoms and their movements "in itself", but only about the correlation to the measurements procedures, produced by man with scientific instruments. As Heisenberg said, "the subject of research is not already the nature in itself, but the nature, as being the subject of human questioning; because of this, the man inevitably meets himself" and "actually, the talk is not about the pattern of nature, but about our relation to nature",

The twentieth century philosophy has realized that it is impossible to build up the doctrine of the objective nature irrespectively to the procedures of observation, measurement, experiment and theoretical reflections. With all this, attention is paid to the importance of the comprehension of various ontological models of modern science, taking into account the fact that nature is to be thought otherwise as in Naturphilosophie; the previous dismembering of nature in the subject and the object of cognition, in worlds internal and external, is inadmissible.

Contemporary philosophy realizes that the 'view of nature' is in fact a view of our interactions with nature. Science itself is interwoven in the net of spiritual practical correlations of man and nature. The nature is the only moment of interaction between the man and the world outward. It is the extreme notion being filled with concrete historical, social and cultural sense. Nature is involved into the smithery of human activity and human relations; it cannot be understood without these relations, out of historical cultural sphere. Nature becomes the participant of human questioning which grows in a certain social and cultural context and carries with itself its signs. The philosophy of nature begins to be built up on the basis of ontology of history, on the basis of the comprehension of ultimate characteristics of historic processes.

The idea of fundamental "ontological" coherence between the subject and the object of studying, of the fixation of the processes of self-organization not only in the inorganic and organic nature, but in the whole Universe (synergetics of H. Haken and I. Prigogine); the E. Jantsch's ideas about structural community of cosmological, biological and scientific technical evolution (the idea of co-evolution of man and nature); the analysis of naturalgenetic sources of various forms of the social conduct of animals and man (social biology); the emerging of social ecology, investigating the influence of man on natural ecosystems, all these elements have widened the possibilities of the philosophy of nature and essentially complicated its problems.

At the same time, the setting in the philosophy of nature of new methodological and theoretical principles, such as the idea of the directional character of time and of the inconvertibility of natural processes, the works with unique and inimitable objects of research in cosmology, ecology and other sciences gives us hope that the philosophy of nature which comes into life at the beginning of the new millennium, will put bridges not only between the existentialist philosophy of life and the comprehension of nature, but also between natural scientific and humanitarian cultures, between principles and ultimate bases of sciences and the humanities.

${ }^{2}$ Ibid. 